\title{
Neutral Endopeptidase and Kininase II Mediate Glucocorticoid Inhibition of Neurogenic Inflammation in the Rat Trachea
}

\author{
G. Piedimonte, D. M. McDonald, ${ }^{*}$ and J. A. Nadel ${ }^{\text {ts }}$ \\ Cardiovascular Research Institute and Departments of ${ }^{\ddagger}$ Medicine, ${ }^{\S}$ Physiology, and ${ }^{*}$ Anatomy, \\ University of California, San Francisco, San Francisco, California 94143
}

\begin{abstract}
Glucocorticoids inhibit plasma extravasation induced in the rat tracheal mucosa by substance $P$ and other tachykinins released from sensory nerves. This study was performed to determine whether this antiinflammatory effect of glucocorticoids is mediated by the tachykinin-degrading enzymes neutral endopeptidase (NEP) and kininase II (angiotensin converting enzyme, ACE). In addition, we studied the effect of dexamethasone on a nonpeptide inflammatory mediator, platelet-activating factor (PAF), which is not degraded by NEP or ACE. Adult male pathogen-free $F 344$ rats were treated for 2 d with dexamethasone $(0.5 \mathrm{mg} / \mathrm{kg}$ per $\mathrm{d}$ i.p.), or with the vehicle used to dissolve the steroid. The magnitude of plasma extravasation produced by an intravenous injection of substance $P(5 \mu \mathrm{g} / \mathrm{kg})$ or PAF (10 $\mu \mathrm{g} / \mathrm{kg}$ ) was then assessed by using Monastral blue pigment as an intravascular tracer. The role of NEP and ACE activities in the changes produced by dexamethasone was investigated by examining the effect of the selective inhibitors of these enzymes, phosphoramidon and captopril. Dexamethasone reduced the substance P-induced extravasation by $57 \%$ but did not affect the PAF-induced extravasation. The suppressive effect of dexamethasone on substance $P$-induced extravasation was completely reversed by simultaneously inhibiting NEP and ACE activities, but the inhibition of these enzymes had no effect on PAF-induced extravasation, regardless of whether the rats were pretreated with dexamethasone or not. These results suggest that NEP and ACE mediate a selective inhibitory effect of glucocorticoids on neurogenic plasma extravasation. ( $J$. Clin. Invest. 1991. 88:40-44.) Key words: enkephalinase, EC 3.4.15.1 angiotensin I-converting enzyme, EC 3.4.24.11 • enzyme modulation $\bullet$ dexamethasone $\bullet$ vascular permeability
\end{abstract}

\section{Introduction}

Tachykinins, particularly substance $P$, released upon stimulation of the sensory nerves increase the permeability of venules of the tracheobronchial circulation and thus produce plasma extravasation and mucosal edema $(1,2)$. This is part of an acute inflammatory reaction known as "neurogenic inflammation," which may have an important role in the pathophysiology of asthma (3). The effect of substance P on vascular perme-

Address correspondence to Dr. Jay A. Nadel, Cardiovascular Research Institute, Box 0130, University of California, San Francisco, CA 94143-0130.

Received for publication 17 October 1990 and in revised form 23 January 1991.

J. Clin. Invest.

(c) The American Society for Clinical Investigation, Inc. 0021-9738/91/07/0040/05 \$2.00

Volume 88, July 1991, 40-44 ability in the respiratory tract is modulated by the activity of neutral endopeptidase (NEP, ${ }^{1}$ enkephalinase, EC 3.4.24.11) (reviewed in 4), a membrane-bound enzyme that cleaves and thus inactivates tachykinins. Substance $P$ is also inactivated by kininase II (angiotensin I-converting enzyme, ACE, EC 3.4.15.1) (reviewed in 5), but the role of this enzyme in the regulation of airway vascular permeability has not yet been explored. Both ACE (6) and NEP (unpublished observation) are expressed in the postcapillary venules, where mediator-induced plasma extravasation occurs $(7,8)$.

We have shown previously that neurogenic plasma extravasation in the airway mucosa is inhibited by glucocorticoids in a dose-dependent fashion (9). Glucocorticoids induce the expression of both NEP $(10)$ and $\operatorname{ACE}(11,12)$ in cultured cells, and increased degradation of tachykinins by these two enzymes may be a component of the antiinflammatory activity of glucocorticoids.

We hypothesized that glucocorticoid-induced upregulation of the two peptide-degrading enzymes, by increasing the cleavage of neuropeptides such as substance $P$, decreases the effectiveness of these peptides in increasing vascular permeability. Because of the technical difficulty of assessing enzymatic activity in the postcapillary venule in vivo, in this study we examined the effect of a selective inhibitor of NEP, phosphoramidon (13), and a selective inhibitor of kininase II, captopril (14), on the inhibition produced by dexamethasone $(0.5 \mathrm{mg} / \mathrm{kg}$ per $\mathrm{d}$ for $2 \mathrm{~d}$ ) on the increase of tracheal vascular permeability evoked by an injection of substance $P$. Changes in the permeability of the tracheal microvasculature were measured by injecting intravascularly Monastral blue pigment, a tracer that leaks out of airway blood vessels only when their permeability is increased (15). In addition, we studied the effect of another mediator that increases tracheal vascular permeability, platelet-activating factor (PAF) (16), a phospholipid which, unlike substance $P$, is not cleaved by NEP or by ACE. We reasoned that if glucocorticoids act by upregulating these enzymes, then substance $P$-induced extravasation would be decreased by dexamethasone treatment but PAF-induced extravasation would not. Furthermore, inhibitors of NEP and ACE should reverse completely the glucocorticoid-induced inhibition of extravasation produced by substance $P$, but these inhibitors should have no effect on PAF-induced extravasation.

Our results show that dexamethasone, at the dose used in our experiments, markedly inhibits the plasma extravasation in the tracheal mucosa produced by substance $P$, but has no effect on PAF. Furthermore, the simultaneous inhibition of NEP and ACE completely reverses the effect of dexamethasone on substance P-induced extravasation.

1. Abbreviations used in this paper: $\mathrm{ACE}$, angiotensin 1-converting enzyme (kininase II, EC 3.4.15.1); NEP, neutral endopeptidase (enkephalinase, EC 3.4.24.11); PAF, platelet-activating factor. 


\section{Methods}

Animals. We used a total of 92 adult male pathogen-free F344 rats (12 wk of age, average body wt $258 \mathrm{~g}$ ) from Bantin and Kingman, Inc., Fremont, CA. The rats were housed in autoclaved plastic cages isolated by static filters and placed inside a laminar flow rack enclosure (Lab Products Inc., Maywood, NJ) to prevent respiratory tract infection $(9,17)$.

Pretreatment. To determine the dose-response effect of dexamethasone against substance $P$, three groups of five rats were treated for $2 \mathrm{~d}$ with $0.25,0.5$, and $1 \mathrm{mg} / \mathrm{kg}$ per d of dexamethasone sodium phosphate (American Regent Inc., Shirley, NY). The dexamethasone was administered in four intraperitoneal injections: the first injection was given in the afternoon of the first day, the second and third injections were given in the morning and in the afternoon of the second day, and the last injection was given in the morning of the final experimental day. A group of five control rats received the vehicle used to dissolve dexamethasone (sodium sulfite anhydrous, $1 \mathrm{mg} / \mathrm{ml}$; sodium citrate anhydrous, $19.4 \mathrm{mg} / \mathrm{ml}$; benzyl alcohol, $1 \% \mathrm{vol} / \mathrm{vol} ; \mathrm{pH} 7.4$ ), according to the protocol of administration described above.

Studies of the effect of phosphoramidon and captopril on substance P-induced extravasation (23 rats) and studies of the effect of dexamethasone on PAF-induced extravasation (10 rats) were performed on rats treated for $2 \mathrm{~d}$ with $0.5 \mathrm{mg} / \mathrm{kg}$ per d of dexamethasone. These two groups of dexamethasone-treated rats were compared with two groups of vehicle-treated controls consisting of 26 and 10 rats, respectively.

Description of the experiments. At the end of the pretreatment period, the rats were anesthetized with sodium methohexital $(70 \mathrm{mg} / \mathrm{kg}$ i.p.), alternating between dexamethasone-pretreated and vehicle-pretreated animals.

To assess vascular permeability, we injected Monastral blue pigment intravenously (3\% suspension in $0.9 \% \mathrm{NaCl}$; Sigma Chemical Co., St. Louis, MO). The particles of pigment leave the bloodstream only through gaps that form in the venular endothelium in response to inflammatory mediators (15). The particles that extravasate remain trapped within the vessel wall, thereby labeling the sites of extravasation. Previous studies have shown that no Monastral blue extravasation occurs in the absence of inflammatory stimuli in the tracheas of rats pretreated with dexamethasone or with its vehicle (9). Before the experiments, the pigment was sonicated in an ultrasonic cleaner for 5 min and passed through a 5- $\mu \mathrm{m}$ filter (Millipore/Continental Water Systems, Bedford, MA).

The injection of the tracer $(30 \mathrm{mg} / \mathrm{kg}$ i.v. over $5 \mathrm{~s})$ was followed immediately by an intravenous injection of substance $P$ (Peninsula Laboratories, Inc., Belmont, CA) dissolved in $5 \mathrm{mM}$ acetic acid containing $0.9 \% \mathrm{NaCl}$. We used a dose of substance $P(5 \mu \mathrm{g} / \mathrm{kg}$ i.v. over 20 s) which has been shown to produce a moderate increase vascular permeability in the rat trachea (18). A group of 20 rats received an injection of PAF, to determine whether the effect of dexamethasone $(0.5$ $\mathrm{mg} / \mathrm{kg}$ per d) is selective for neuropeptide-induced extravasation. The dose of PAF used for this study (10 $\mu \mathrm{g} / \mathrm{kg}$ i.v. over $20 \mathrm{~s}$ ) was chosen because our preliminary experiments showed that the magnitude of the increase in vascular permeability to Monastral blue produced in rat tracheas by this dose is similar to that produced by $5 \mu \mathrm{g} / \mathrm{kg}$ i.v. of substance P. PAF (1-O-hexadecyl-2-acetyl-sn-glycero-3-phosphorylcholine; Bachem Inc., Torrance, CA) was prepared as a stock solution $(1 \mathrm{mg} / \mathrm{ml})$ in $100 \%$ ethanol, stored at $-80^{\circ} \mathrm{C}$, and then diluted to the final concentration $(10 \mu \mathrm{g} / \mathrm{ml})$ on the experimental day using $0.9 \%$ $\mathrm{NaCl}$ containing $0.35 \%$ BSA (Sigma Chemical Co.).

To explore the possible involvement of NEP and ACE in the mechanism of dexamethasone-induced inhibition of neurogenic plasma extravasation, we used the selective NEP inhibitor phosphoramidon $(N$ [ $\alpha$-rhamnopyranosyloxyhydroxyphosphinyl]-L-leucyl-L-tryptophan; Sigma Chemical Co.) (13) and the selective ACE inhibitor captopril ([2S]-1-[3-mercapto-2-methylpropionyl]-L-proline; Sigma Chemical Co.) (14). Captopril alone (2.5 or $5 \mathrm{mg} / \mathrm{kg}$ ), phosphoramidon alone $(2.5$ or $5 \mathrm{mg} / \mathrm{kg}$ ), or captopril followed immediately by phosphoramidon $(2.5 \mathrm{mg} / \mathrm{kg}$ of each), was injected intravenously over $10 \mathrm{~s}, 5 \mathrm{~min}$ before the injection of the tracer. Control rats received an injection of $0.9 \%$ $\mathrm{NaCl}(1 \mathrm{ml} / \mathrm{kg}$ i.v.), which was the solvent used to dissolve both drugs. A group of three rats was treated with captopril and phosphoramidon $(2.5 \mathrm{mg} / \mathrm{kg}$ of each) and $5 \mathrm{~min}$ later received an injection of the vehicle used to dissolve substance $\mathbf{P}(1 \mathrm{ml} / \mathrm{kg}$ i.v. $)$, to determine whether the two inhibitors had any direct effect on vascular permeability.

5 min after the injection of the tracer, the chest was opened, a cannula was inserted into the ascending aorta through the left ventricle, and the circulation was perfused for $2 \mathrm{~min}$ with fixative (1\% paraformaldehyde in $50 \mathrm{mM}$ phosphate buffer containing $0.85 \% \mathrm{NaCl}, \mathrm{pH}$ 7.4) at a pressure of $120 \mathrm{mmHg}$. The segment of trachea from the fifth cartilaginous ring to the carina, separated from adjacent structures and opened along the ventral midline, was prepared as a whole mount following a procedure described previously (2).

The area density of Monastral blue-labeled vessels in the tracheal mucosa was estimated using stereological point counting (19). Point counts were made by superimposing a computer-generated grid of 51 points spaced at $25-\mathrm{mm}$ intervals on the televised image of the specimens magnified 380 times with a stereomicroscope $(9,17)$. Monastral blue area density was expressed as the average of values measured in 20 regions (each measuring $0.3 \mathrm{~mm}^{2}$ in area) located between cartilaginous rings, from ring 5 to ring 25 , on the right side of each tracheal whole mount. Previous observations have shown that measurements of vascular permeability obtained with this technique correlate closely with spectrophotometric measurements of albumin extravasation obtained using Evans blue dye (9).

Statistical analysis. All data reported in this study are expressed as the mean \pm standard error of the mean. Mean values of stereological measurements of Monastral blue extravasation were analyzed by twoway analysis of variance (20). Multiple a posteriori comparisons between means were performed by the Student-Newman-Keuls test (20). Differences having a $P$ value $<0.05$ were considered significant.

\section{Results}

In rats pretreated with only the vehicle of dexamethasone, the injection of either captopril or phosphoramidon $(2.5 \mathrm{mg} / \mathrm{kg}$ of either drug individually) produced a significant potentiation of the substance P-induced extravasation of Monastral blue in the tracheal mucosa (Fig. 1, left columns; $P<0.01$ ). The extravasation of tracer in rats that received a higher dose $(5 \mathrm{mg} / \mathrm{kg})$ of captopril (area density $=35.1 \pm 5.9 \%$ ) or phosphoramidon (area density $=34.7 \pm 1.9 \%$ ) was not significantly different from that found in rats that received $2.5 \mathrm{mg} / \mathrm{kg}$ of either drug $(n=3$ rats per group). However, the combination of captopril and phosphoramidon $(2.5 \mathrm{mg} / \mathrm{kg}$ of each $)$ caused an even greater potentiation of substance P-induced Monastral blue extravasation than did either drug individually regardless of the dose (Fig. 1, left; solid column; $P<0.05$ ). No Monastral blue-labeled vessels were found in the tracheas of rats that received an injection of only the vehicle of substance $P$ after the administration of captopril and phosphoramidon.

Dexamethasone reduced in a dose-dependent manner the increase in vascular permeability produced in the rat tracheal mucosa by an intravenous injection of substance $P$. Compared to vehicle-treated rats that received substance $\mathbf{P}$ (area density of Monastral blue-labeled blood vessels $=22.2 \pm 1.9 \%$; mean \pm SEM; $n=5$ rats), substance P-induced extravasation was significantly inhibited $(P<0.01)$ by $2 \mathrm{~d}$ of pretreatment with dexamethasone at concentrations of $0.25 \mathrm{mg} / \mathrm{kg}$ per d $(9.8 \pm 2.3 \%), 0.5 \mathrm{mg} / \mathrm{kg}$ per d $(9.5 \pm 2.1 \%$; see Fig. 1, open columns), and $1 \mathrm{mg} / \mathrm{kg}$ per d $(4.9 \pm 1.2 \% ; n=5$ rats per group).

In rats pretreated with $0.5 \mathrm{mg} / \mathrm{kg}$ per d of dexamethasone, the administration of either captopril alone or phosphorami- 


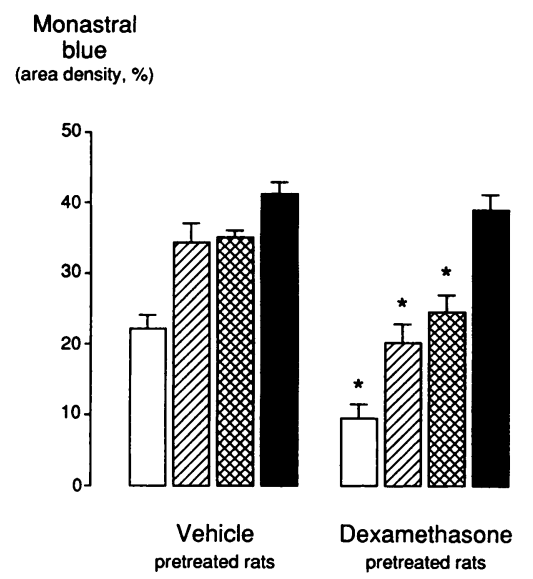

Figure 1. Effect of captopril (inhibitor of kininase II; $2.5 \mathrm{mg} / \mathrm{kg}$ i.v.), phosphoramidon (inhibitor of neutral endopeptidase; $2.5 \mathrm{mg} / \mathrm{kg}$ i.v.), or both on the amount of Monastral blue extravasation from tracheal blood vessels induced by substance $P$ ( $5 \mu \mathrm{g} / \mathrm{kg}$ i.v.). Rats were pretreated with the vehicle of dexamethasone (left columns) or with dexamethasone $(0.5$ $\mathrm{mg} / \mathrm{kg}$ per d i.p. for $2 \mathrm{~d}$; right columns). Values

are mean $\pm \mathrm{SEM} ; n=5-6$ rats per group. Asterisks mark significant differences between dexamethasone-treated rats and the corresponding vehicle-treated controls $\left({ }^{*} P<0.01\right)$. In vehicle-pretreated rats, substance $P$-induced extravasation was potentiated by captopril alone or by phosphoramidon alone $(P<0.01)$ and was further potentiated by the combination of both inhibitors $(P<0.05)$. Dexamethasone reduced substance $P$-induced extravasation, and this effect was only partially reversed by captopril alone or by phosphoramidon alone. However, the combination of the two inhibitors completely abolished the inhibitory effect of dexamethasone. $\square$, saline; 农, captopril; phosphoramidon; $\mathbf{\square}$, captopril + phosphoramidon.

don alone $(2.5 \mathrm{mg} / \mathrm{kg})$ increased the extravasation of Monastral blue in the tracheal mucosa (Fig. 1, right columns; $P$ $<0.01$ ), but the extravasation of tracer was still significantly less than in the corresponding vehicle-treated controls $(P$ $<0.01)$. As with vehicle-treated rats, a higher dose $(5 \mathrm{mg} / \mathrm{kg})$ of either captopril (area density $=24.6 \pm 3.8 \%$ ) or phosphoramidon (area density $=25.5 \pm 0.2 \%$ ) did not further increase the extravasation of Monastral blue ( $n=3$ rats per group). However, the combination of captopril and phosphoramidon $(2.5$ $\mathrm{mg} / \mathrm{kg}$ of each) completely reversed the effect of dexamethasone on substance P-induced extravasation. In fact, after the injection of both inhibitors, the amount of Monastral blue extravasation in rats treated with dexamethasone (Fig. 1, right; solid column) was not statistically different from vehicletreated control rats.

The magnitude of Monastral blue extravasation produced by the dose of PAF ( $10 \mu \mathrm{g} / \mathrm{kg})$ used in this study was similar to that produced by $5 \mu \mathrm{g} / \mathrm{kg}$ substance P (Fig. 2, left; open columns). However, the dose of dexamethasone that inhibited by $57 \%$ the substance P-induced extravasation $(0.5 \mathrm{mg} / \mathrm{kg}$ per d for $2 \mathrm{~d}$ ) had no effect on the extravasation of tracer induced by PAF (Fig. 2, right; open columns). Furthermore, the PAF-induced extravasation was not affected by the administration of both captopril and phosphoramidon, either in vehicle-treated rats or in dexamethasone-treated rats (Fig. 2, solid columns).

\section{Discussion}

Influence of neutral endopeptidase and kininase II inhibitors on substance P-induced plasma extravasation. We found that inhibitors of the tachykinin-degrading enzymes NEP and ACE potentiate the extravasation produced in the rat tracheal mucosa by substance P. Furthermore, we found that the simultaneous inhibition of both of these enzymes potentiates the effect

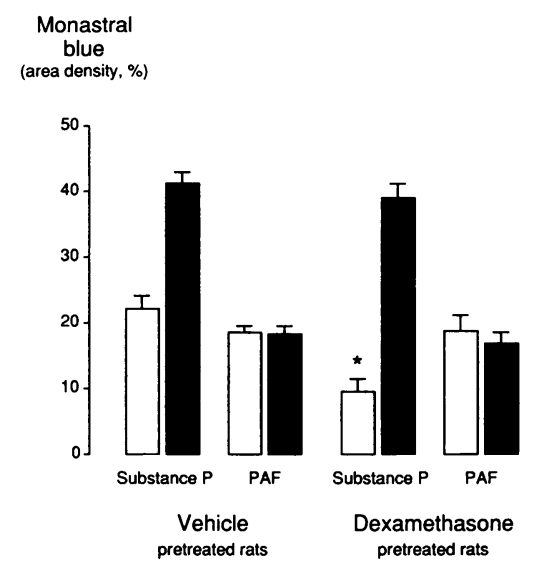

Figure 2. Effect of captopril and phosphoramidon $(2.5 \mathrm{mg} / \mathrm{kg}$ of each i.v.) on the amount of Monastral blue extravasation from tracheal blood vessels produced by substance $P(5 \mu \mathrm{g} / \mathrm{kg}$ i.v. $)$ or by PAF $(10 \mu \mathrm{g} /$ kg i.v.). Rats were pretreated with the vehicle of dexamethasone (left columns) or with dexamethasone (right columns). Values are mean $\pm \mathrm{SEM} ; n=5$ rats per group. The asterisk

marks a significant difference between dexamethasone-treated rats injected with SP and the corresponding vehicle-treated controls $\left({ }^{*} P\right.$ $<0.01$ ). In vehicle-pretreated rats, substance $P$-induced extravasation was potentiated by the combination of captopril and phosphoramidon $(P<0.01)$, while PAF-induced extravasation was unaffected. Dexamethasone reduced substance $P$-induced extravasation $(P$ $<0.01$ ), but had no effect on PAF-induced extravasation. Furthermore, the combination of the two inhibitors abolished the effect of dexamethasone on SP-induced extravasation, but did not change PAF-induced extravasation. $\square$, saline; $\mathbf{a}$, captopril + phosphoramidon.

of substance $\mathbf{P}$ more than does a maximally effective dose of either inhibitor by itself.

Among the peptidases that can potentially inactivate tachykinins, NEP $(21,22)$ and ACE $(22)$ were studied because several observations indicate that they may have particular relevance in the control of tachykinin activity. Both NEP and ACE are ectoenzymes that are bound to the plasma membrane of target cells of peptide mediators (reviewed in 4, 5). Specific NEP immunoreactivity is present in postcapillary venules of the rat tracheal mucosa (unpublished observations), the sites of tachykinin-induced extravasation. Similarly, it has been shown that ACE activity is expressed in cultured rat venular endothelium (6).

NEP has been shown to play an important role in the modulation of the biological effects of tachykinins in the airways. This study confirms the observation (4) that NEP inhibitors potentiate neurogenic plasma extravasation. ACE has been shown to modulate the effect of intravenous substance $P$ on the contraction of guinea pig airway smooth muscle in vivo (23). The effect of ACE inhibitors on mediator-induced plasma extravasation has been investigated in the skin of rodents, but the reported data are contradictory $(24,25)$ : captopril has been reported to both potentiate (25) and to inhibit (by an ACE-independent mechanism) (24) the extravasation of plasma induced by bradykinin, which is a good substrate for ACE.

We found that a selective inhibitor of ACE (captopril) potentiates substance P-induced extravasation. Thus, both NEP and ACE inhibitors potentiate the substance $P$ effect on vascular permeability. When the combination of NEP and ACE inhibitors was used together, the effect of substance $P$ was greater than when only a single inhibitor was used. We suggest that, when only one peptidase is inhibited, the remaining enzyme may still limit substance $P$ activity partially. Only when the activity of both peptidases is inhibited can substance $P$ exert a maximal effect. 
Influence of neutral endopeptidase and kininase II inhibitors on glucocorticoid suppression of neurogenic extravasation. We showed previously that dexamethasone inhibits the extravasation produced in the trachea of rats by an intravenous injection of exogenous substance $P$ or of capsaicin (9), a drug that releases endogenous substance $P$ from sensory nerves (26). In this study, we examined the possibility that this inhibition involves increased activity of tachykinin degrading enzymes.

We found that dexamethasone inhibition of substance Pinduced extravasation is partially reduced by a selective inhibitor of NEP or by a selective inhibitor of ACE. However, the combination of both inhibitors reverses the effect of dexamethasone completely. One interpretation of these results is that dexamethasone affects the activity of both enzymes: if the activity of both enzymes is increased, then the inhibition of only one enzyme would be predicted to reverse only partially the suppressive effect of dexamethasone.

Differences between substance $P$ - and $P A F$-induced plasma extravasation. Dexamethasone reduced substance P-induced plasma extravasation in the tracheal mucosa in a dose-dependent fashion, confirming our previous observations (9). Signifcant inhibition was produced by a dose of dexamethasone as low as $0.25 \mathrm{mg} / \mathrm{kg}$ per $\mathrm{d}$ given for $2 \mathrm{~d}$. However, the dose of dexamethasone that inhibited by $>50 \%$ the substance P-induced extravasation $(0.5 \mathrm{mg} / \mathrm{kg}$ per $\mathrm{d}$ for $2 \mathrm{~d})$ had no effect on the plasma extravasation induced by an intravenous injection of PAF. Furthermore, PAF-induced extravasation was not affected by the combined inhibition of NEP and ACE. These observations suggest that the dose of dexamethasone used in this study protects tracheal postcapillary venules by increasing tachykinin degradation without affecting the responsiveness of the venular endothelium to the nonpeptide inflammatory mediator, PAF.

A preliminary report indicates that a high dose of dexamethasone $(8 \mathrm{mg} / \mathrm{kg})$ can block PAF-induced extravasation in the rat airways (27). If confirmed, this observation suggests that the mechanism of the antiinflammatory activity of glucocorticoids in the airways is dose-related, and that higher doses of dexamethasone can produce a broader, less specific protection of the tracheobronchial microcirculation against inflammatory mediators.

Glucocorticoid inhibition of plasma extravasation: possible mechanisms. Mediator-induced plasma extravasation is known to occur in postcapillary venules $(7,8)$ and is believed to be due to conformational changes of endothelial cells (28). It has been suggested that glucocorticoids inhibit mediator-induced extravasation through the synthesis of inhibitory proteins that oppose the conformational changes of endothelial cells (29-31). Our present observation that the same dose of dexamethasone that markedly inhibits substance P-induced extravasation has no effect on PAF-induced extravasation is inconsistent with this hypothesis.

We considered an alternative explanation for the suppressive effect of corticosteroids of substance P-induced extravasation: we hypothesized that glucocorticoids upregulate peptidases, thereby increasing the rate of inactivation of this neuropeptide. This hypothesis is based on previous studies in cultured cells: glucocorticoids induce an increase in NEP gene expression and in NEP activity in cultured human airway epithelial cells (10). Similarly, glucocorticoids induce ACE activity in cultures of rabbit alveolar macrophages (11), bovine endothelial cells (12), and human monocytes (32). Pretreatment with dexamethasone results in an increase of ACE activity in homogenates of rat lungs (12). The fact that the glucocorticoid effect on substance P-induced extravasation is completely abolished by the inhibition of NEP and ACE suggests that an increase in the activity of these enzymes mediates this effect of glucocorticoids. The site of the glucocorticoid action on these enzymes in the present studies is unknown.

Substance $\mathbf{P}$ and other neuropeptides are released upon stimulation of the sensory nerves and produce "neurogenic" extravasation. Many stimuli, such as cigarette smoke and various inhaled irritants (33), or hypertonic saline (34), induce plasma extravasation by stimulating the release of neuropeptides from these sensory nerves. Similarly, various inflammatory mediators, such as histamine and bradykinin, also cause the release of substance $P$ and other neuropeptides from the lungs (35). Prevention of the release of these neuropeptides reduces the effect of histamine on airway vascular permeability $(26,33)$. Thus, glucocorticoids may inhibit plasma extravasation produced by many inflammatory stimuli by inhibiting the effect of secondarily released neuropeptides.

In conclusion, our results suggest that the enzymes neutral endopeptidase and kininase II mediate glucocorticoid-induced inhibition of the plasma extravasation produced in the tracheal mucosa by substance $P$, which is an important mediator of neurogenic inflammation. This antiinflammatory effect is produced by a dose of dexamethasone that does not diminish the plasma extravasation induced by PAF. This suppressive effect of glucocorticoids may be important in the antiinflammatory effects of these drugs in various inflammatory states.

\section{Acknowledgments}

We thank Brooks McDonald for helping with the stereological measurements of Monastral blue extravasation. We also thank Terry Peura for assisting in typing the manuscript.

This study was supported in part by National Institutes of Health Program Project Grant HL-24136.

\section{References}

1. Lundberg, J. M., A. Saria, E. Brodin, S. Rosell, and K. Folkers. 1983. A substance $P$ antagonist inhibits vagally induced increase in vascular permeability and bronchial smooth muscle contraction in the guinea pig. Proc. Natl. Acad. Sci. USA. 80:1120-1124.

2. McDonald, D. M. 1988. Neurogenic inflammation in the rat trachea. I. Changes in venules, leucocytes, and epithelial cells. J. Neurocytol. 17:583-603.

3. Barnes, P. J. 1986. Asthma as an axon reflex. Lancet. i:242-245.

4. Nadel, J. A. 1990. Neutral endopeptidase modulates neurogenic inflammation in airways. In Allergologie Proceedings. In press.

5. Erdös, E. G. 1979. Kininases. In Handbook of Experimental Pharmacology, Vol. XXV Supplement. Springer-Verlag, Berlin, Heidelberg. 427-487.

6. Moyer, C. F., P. A. Dennis, G. Majno, and I. Joris. 1988. Venular endothelium in vitro: isolation and characterization. In Vitro Cell. \& Dev. Biol. 24:359368.

7. Majno, G., and G. E. Palade. 1961. Studies on inflammation. I. The effect of histamine and serotonin on vascular permeability: an electron microscopic study. J. Biophys. Biochem. Cytol. 11:571-604.

8. Majno, G., G. E. Palade, and G. I. Schoefl. 1961. Studies on inflammation, II. The site of action of histamine and serotonin along the vascular tree: a topographic study. J. Biophys. Biochem. Cytol. 11:607-625.

9. Piedimonte, G., D. M. McDonald, and J. A. Nadel. 1990. Glucocorticoids inhibit neurogenic plasma extravasation and prevent virus-potentiated extravasation in the rat trachea. J. Clin. Invest. 86:1409-1415.

10. Borson, D. B., and D. C. Gruenert. 1991. Glucocorticoids induce neutra endopeptidase in transformed human tracheal epithelial cells. Am. J. Physiol. 260 (Lung Cell. Mol. Physiol.4):L83-L89.

11. Friedland, J., C. Setton, and E. Silverstein. 1977. Angiotensin converting enzyme: induction by steroids in rabbit alveolar macrophages in culture. Science (Wash. DC). 197:64-65. 
12. Mendelsohn, F. A. O., C. J. Lloyd, C. Kachel, and J. W. Funder. 1982. Induction by glucocorticoids of angiotensin converting enzyme production from bovine endothelial cells in culture and rat lung in vivo. J. Clin. Invest. 70:684692.

13. Hudgin, R. L., S. E. Charleson, M. Zimmerman, R. Mumford, and P. L. Wood. 1981. Enkephalinase: selective peptide inhibitors. Life Sci. 29:2593-2601.

14. Ondetti, M. A., B. Rubin, and D. W. Cushman. 1977. Design of specific inhibitors of angiotensin-converting enzyme: new class of orally active antihypertensive agents. Science (Wash. DC). 196:441-444.

15. Joris, I., U. DeGirolami, K. A. Wortham, and G. Majno. 1982. Vascular labeling with Monastral blue B. Stain Technol. 57:177-183.

16. Evans, T. W., K. F. Chung, D. F. Rogers, and P. J. Barnes. 1987. Effect of platelet-activating factor on airway vascular permeability: possible mechanisms. J. Appl. Physiol. 63:479-484.

17. Piedimonte, G., J. A. Nadel, E. Umeno, and D. M. McDonald. 1990 Sendai virus infection potentiates neurogenic inflammation in the rat trachea. $J$. Appl. Physiol. 68:754-760.

18. McDonald, D. M. 1988. Respiratory tract infections increase susceptibility to neurogenic inflammation in the rat trachea. Am. Rev. Respir. Dis. 137:1432-1440.

19. Weibel, E. R. 1979. Stereological methods. Practical methods for biological morphometry. Academic Press Ltd., London.

20. Zar, J. H. 1984. Two-factor analysis of variance. In Biostatistical Analysis. Prentice-Hall, Inc., Englewood Cliffs, NJ. 206-235.

21. Matsas, R., I. S. Fulcher, A. J. Kenny, and A. J. Turner. 1983. Substance P and [Leu] enkephalin are hydrolyzed by an enzyme in pig caudate synaptic membranes that is identical with the endopeptidase of kidney microvilli. Proc. Natl. Acad. Sci. USA. 80:3111-3115.

22. Skidgel, R. A. S. Engelbrecht, A. R. Johnson, and E. G. Erdös. 1984 Hydrolysis of substance $P$ and neurotensin by converting enzyme and neutral endopeptidase. Peptides (Elmsford). 5:769-776

23. Shore, S. A., N. P. Stimler-Gerard, S. R. Coats, and J. M. Drazen. 1988 Substance P-induced bronchoconstriction in the guinea pig: enhancement by inhibitors of neutral metalloendopeptidase and angiotensin-converting enzyme. Am. Rev. Respir. Dis. 137:331-336.
24. Fantone, J. C., D. Schrier, and B. Weingarten. 1982. Inhibition of vascular permeability changes in rats by captopril. J. Clin. Invest. 69:1207-1211.

25. Boura, A. L. A., and A. P. Svolmanis. 1984. Converting enzyme inhibition in the rat by captopril is accompanied by potentiation of carrageenin-induced inflammation. Br. J. Pharmacol. 82:3-8.

26. Saria, A., J. M. Lundberg, G. Skofitsch, and F. Lembeck. 1983. Vascular protein leakage in various tissues induced by substance $P$, capsaicin, bradykinin, serotonin, histamine, and by antigen challenge. Naunyn-Schmiedeberg's Arch. Pharmacol. 324:212-218.

27. Boschetto, P., D. F. Rogers, and P. J. Barnes. 1989. Corticosteroid inhibition of PAF- and antigen-induced plasma exudation in rat airways in vivo. Am Rev. Respir. Dis. 139:A328 (Abstr.)

28. Majno, G., S. M. Shea, and M. Leventhal. 1969. Endothelial contraction induced by histamine-type mediators. An electron microscopic study. J. Cell Biol. 42:647-672.

29. Tsurufuji, S., K. Sugio, and F. Takemasa. 1979. The role of glucocorticoid receptor and gene expression in the anti-inflammatory action of dexamethasone. Nature (Lond.). 280:408-410.

30. Oyanagui, Y. 1983. Physiological regulation of vascular permeability by endogenous glucocorticoids and active oxygen. Inflammation. 7:81-89.

31. Carnuccio, R., M. Di Rosa, B. Guerrasio, T. Iuvone, and L. Sautebin 1987. Vasocortin: a novel glucocorticoid-induced anti-inflammatory protein. $\mathrm{Br}$. J. Pharmacol. 90:443-445.

32. Vuk-Pavlovic, Z., T. J. Kreofsky, and M. S. Rohrbach. 1989. Characteristics of monocyte angiotensin-converting enzyme (ACE) induction by dexamethasone. J. Leukocyte Biol. 45:503-509.

33. Lundberg, J. M., and A. Saria. 1983. Capsaicin-induced desensitization of airway mucosa to cigarette smoke, mechanical and chemical irritants. Nature (Lond.). 302:251-253.

34. Umeno, E., D. M. McDonald, and J. A. Nadel. 1990. Hypertonic saline increases vascular permeability in the rat trachea by producing neurogenic inflammation. J. Clin. Invest. 85:1905-1908.

35. Saria, A., C.-R. Martling Z. Yan, E. Theodorsson-Norheim, R. Gamse and J. M. Lundberg. 1988. Release of multiple tachykinins from capsaicin-sensitive sensory nerves in the lung by bradykinin, histamine, dimethylphenyl piperazinium, and vagal nerve stimulation. Am. Rev. Respir. Dis. 137:1330-1335. 